\title{
Theoretical study of tetrad effects observed in REE distribution coefficients between marine Fe-Mn deposit and deep seawater, and in REE(III)-carbonate complexation constants
}

\author{
AtSUyUKi OHTA and IWAO KAWABE
}

Geochemical Journal, Vol. 34, No. 6, pp. 455-473, 2000

The activity and activity coefficient in Eqs. (10) and (12) and the second line from the bottom-right paragraph on page 460 must be written respectively as follows.

$$
a_{\mathrm{M}(\mathrm{OH})_{3} \cdot n \mathrm{H}_{2} \mathrm{O}} \text { and } \lambda_{\mathrm{M}(\mathrm{OH})_{3} \cdot n \mathrm{H}_{2} \mathrm{O}} \cdot
$$

Equation (23) is incorrect, and should be read:

$$
\omega=\left(K_{2} / K_{1}\right) \cdot a_{\mathrm{CO}_{3}^{2-}}
$$

In the fourth line from the top-left paragraph on page 462, "Eqs. (22) and (23)" should be corrected as "Eqs. (20) and (21)".

In the eleventh line from the top-left paragraph on page 462, "Equations (20) and (24)" should be replaced by "Equations (18) and (24)".

In the eighth line from the bottom-left paragraph on page 465, "Eqs. (20) and (24)" should be replaced by "Eqs. (18) and (24)".

In Fig. 7, the values of 3, 4 and 5 of the vertical axis on the left-hand side should be corrected as 4, 5 and 6 , respectively.

In the seventh line from the top-left paragraph on page 470, "Equation (20)" should be replaced by "Equation (18)". 